\title{
Linguo-Didactic Foundations of Teaching Emotional and Evaluative Lexics of the Russian Language to the Turkic-Speaking Audience
}

\author{
Rashida Hafizovna Tirigulova ${ }^{1}$, Oksana Vyacheslavovna Zakirova ${ }^{1}$, Elmira Rashitovna Ibragimova $^{1}$ \& Evgeniya \\ Leonidovna Pupysheva ${ }^{1}$ \\ ${ }^{1}$ Kazan Federal University, Russian Federation \\ Correspondence: Rashida Hafizovna Tirigulova, Kazanskaya street, 89, Elabuga, 423600, Tatarstan, Russian \\ Federation.
}

$\begin{array}{lr}\text { Received: February 3, } 2015 & \text { Accepted: May 5, } 2015 \quad \text { Online Published: July 30, } 2015 \\ \text { doi:10.5539/ass.v11n19p229 } & \text { URL: http://dx.doi.org/10.5539/ass.v11n19p229 }\end{array}$

\begin{abstract}
The paper addresses issues of teaching emotional and evaluative vocabulary of the Russian language to Turk-speaking students. It also demonstrates the important role of the contrastive-typological approach to their study of the marked lexics. Certain linguo-didactic technologies that allow to form their communicative and cultural competence in the educational process are described. The results of the training experiment prove the effectiveness of the proposed methods of theoretical and practical material presentation. It seems a promising perspective to create an online educational resource for this section.
\end{abstract}

Keywords: a contrastive typological approach, emotionally-appraising vocabulary, emotional lexics, connotative meanings, a derivational group, teaching methods

\section{Introduction}

The educational system of Russia at its different stages implements the federal targeted program "Russian language" for the 2011-2015 years period. It involves work ensuring the realization of the Russian language function as the State language, creating conditions for the Russian language functioning as a vehicle of international communication of Russia nations, as well as studying the quality of non-native speakers' Russian language knowledge while studying at educational institutions (Federal Target Program "Russian language" for 2011-2015 years, 2011).

It is known that in the Tatarstan Republic "language policy is aimed on supporting equal state of Russian and Tatar languages in communication and development of a bilingual person" (Ibragimova \& Tirigulova, 2014, pp. 677-680). Bilingual education is mandatory there, but it does not offer sufficient mastering of the two languages, including Tatars' speaking the Russian language.

With the consideration of these factors, it is necessary to focus attention on the Russian language teaching methodic, in particular, its vocabulary, when working with Tatar students, future teachers of Russian and literature. The study of non-natives' learning the Russian language is often connected with difficulties of the Turk-speaking (Tatar) students' mastering some separate sections of the Russian language.

The problem, as it is known, is created by differences in the native and the studied languages (Tatar language belongs to agglutinative languages, and Russian is a fusional language). The researchers note that "the students' mother tongues belonging to different groups a priori explains that some of the Russian language phenomenon will be perceived and learnt more or less easily, and other phenomena -with huge difficulties" (Bakeeva, 1983, pp. 19-28).

A moment of misunderstanding, difficulties arise in connection with the distinction of cultures behind the languages, that's why the modern methodology of teaching Russian language as non-native is focused on teaching it in the regime of the dialogue of languages as the dialogue of cultures and the formation of students' linguo-cultural competence (Bochina \& Habibulina, 2012; Fattakhova, 2012; Shakirova \& Sabatkoev, 2003, p. 376). In modern linguo-didactic, a contrastive typological approach to the study of both differently structured language systems and the cultures of different peoples is actively applied (Fattakhova \& Yusupova, 2012; Yusupova, 2012).

The object of our study is Turk-speaking students' process of learning the emotional and evaluative lexics of the 
Russian language. Emotionality is one of the main properties of the Russian mentality, which is characterized by the abundance of language means for expressing emotions, emotional tones, assessments (Fedorov, 2012, p. 12).

Subject of research is the process of improving the teaching of marked lexics, applying the contrastive typological approach to its study.

The purpose of our report is to present this approach in studying one of the sections of the course "Modern Russian language"- "Vocabulary in terms of emotional-style coloring" and to show the teaching technology in the educational process, to provide practical linguistic and didactic recommendations.

Research methods are descriptive, comparative, and experimental.

\section{Methodology}

\subsection{On Lexics Specifics and Difficulties of Its Mastering}

Learning the material of this section causes great difficulties for the non-Russian (Tatar) students. The marked vocabulary of the Russian language is often not perceived by Tatar students, i.e. they don't feel it's being marked. Hence, on the one hand, it leads to the misunderstanding of some kinds of information showing the attitude to the described thing in oral and written speech. While on the other hand, it brings various stylistic mistakes when producing their own speech, "avoidance" of marked words, such as nouns with suffixes of subjective assessment. It is connected with the national cultural specifics of the Russian and Tatar languages' vocabularies because "national colorant of the connotative lexics is expressed not in the subject-logical part of their semantic meaning, but in the incremental, usually emotionally-expressive information..." (Fattakhova \& Yusupova, 2012).

It is impossible to achieve fluency in Russian speech and to strengthen the culture of speech without the knowledge of much emotionally tinged vocabulary that contains a component of subjective evaluation. The future teacher must acquire knowledge and bring it to the students, master the techniques of its presentation in the school environment.

To improve the teaching of the subject compared to the traditional, typical presentation of the material, which can be found in the textbooks of "Modern Russian language", the non-Russian audience needs a systematic description of language units, taking into account all the Russians marked words and reflecting the cultural specificity in comparison with the features of their own mother tongue, as well as a special practical training.

\subsection{The Stages of Mastering the Vocabulary}

There can be several stages, in our view, in mastering the designated theme by Turk-speaking students.

The first is the students' reflection of such categories as "assessment", "evaluation", "emotionality". These concepts, being reflected in the language, are directly related to the cultural values of the people and may vary among different cultures. Therefore, when studying theoretical material it is appropriate to discuss this aspect in order to determine national cultural landmarks and comprehension of these concepts in the Russian language.

The next step is to examine the emotional and evaluative vocabulary in semantic aspect, to define certain semantic groups, showing its semantic and stylistic diversity.

Such description is intended to help students navigate in its huge mass, understand the model differences of these words and absorb these units separately, more systematically and consciously, remembering and fixing them in the memory by means of assignment them to a particular category or a subgroup.

Thus, for example, the category of words with positive connotations, has several subgroups: 1) vocabulary with sublime-publicist coloring (apotheosis, epochal, inspire, etc.); 2) vocabulary with high-conversational coloring, which is additionally divided into the following: a) excitement showing lexics (super-brain, tremendous, etc.); b) lexics with a touch of piety (provider, dare etc.); c) lexics with a touch of exaltation (shrine, almighty, etc.); d) lexics with a touch of solemnity (infant, child, etc.). The vocabulary part with the negative connotation has some words with a pejoratively-publicist coloring (some, notorious), words with general-speech disliking shade (slacker, poser), etc.

In order for the classification to contribute to the development and enrichment of the Turk-speaking students' Russian speech, the excessive introduction of linguistic units must be accompanied by vivid speech samples from literature, poetry. To consolidate the topic, the students are asked to perform some tasks, for example: a) to find emotional and evaluative lexics in the given texts (at first with the teacher's help, then independently); b) to make sentences, using this kind of vocabulary; c) to compare the groups of words with connotative values of the Russian language with groups of similar words in the Tatar language, to find common and different features.

The next part is presenting the material on the relation of the marked words to the lexical system of the Russian 
language in general. Particular attention is drawn to the distribution of emotionally and stylistically marked vocabulary among different subject groups. One should show what its specific weight is in the different thematic groups, what type of colored vocabulary belongs to this or that thematic group. For example, the thematic cluster "kinship terms" includes a large number of diminutives, e.g. mommy, daddy, grandpa, sonny, bro, etc. and does not include the pejorative unit.

Accordingly, an attempt is made to track the occurrence of diminutives, pejoratives and other marked words in many thematic groups-"somatic vocabulary", "clothing items", "nature phenomena", "food", "animals", "professions", etc. Similarly, there is a tendency of synonyms groups being filled with coloured members. It can be noted that most synonyms groups have connotation opposition of the members (cf.: rest-hog, eyes (are called differently in Russian from the positive and negative view-Tr.), to conceive - to know the ropes etc.), and some have connotation similarity and uniformity (an hour has three similar roots names in Russian-Tr. $a$ hare- $a$ bunny, etc.). This material should be used in the practice of speech, as well as help the vocational and methodological development of the future Russian language teacher.

In the analysis of thematic groups (fields) and system links of the words (synonymic, antonymic, etc.) one turns to the study of concepts. According to the fair statement of L. G. Sayakhova, "Concept as an integrated unit of language, culture, mental world of a linguistic personality has great training-developing human-teaching capacity, and occupies a worthy place among the linguo-cultural-oriented methods of the Russian language teaching" (Sayakhova, 2014).

\subsection{Ways of Teaching}

Presenting the material makes it possible to implement the problem-based learning. The students can be asked such questions as "Why are/aren't marked words of one type or another among this thematic group units?" When describing each thematic group of synonyms, it is reasonable to encourage students to pick up familiar diminutives and other marked words, to generate statements on a given topic using emotionally colored lexics, to provide examples of speech usability, translation analogs into their native language and finding connotations in their native language.

Alongside with this, electronic-visual means-presentation slides with the tables demonstrating a particular arrangement of emotional words of different types (in clusters), the tables illustrating connotation synonyms and antonyms can be used. Other computerized means of presenting the material, which organically combine with the traditional methods, are also recommended to use in the classroom (Arshinova, 2007; Shalimova, 2013). Information and communication technologies, applied in the classroom, according to S. S. Khromov qualitatively transform "professional diagram" of a teacher of the Russian language as the second language (Khromov, 2012) and at the same time, in our opinion, give methodically "weapon" to the students, future teachers.

\subsection{Word-formation Indexes of Connotations}

The next step is studying the topic "Word-formation groups of marked words". Here an attempt is made to trace how regularly and differentially various words connotation shades are expressed. It is very important for Turk (Tartar) students to remember the information concerning formal indicators of words with additional emotional-style coloring, because the Tatar language unlike the Russian language does not have many of them. First, in the Tatar language (because of its agglutinative nature) there are no prefixes, which in the Russian language can serve to express the connotative values. Secondly, the Tatar language, unlike the Russian one, does not have so many suffixes of subjective evaluation. Studies show that in the Tatar language "suffixes, which have obvious negative emotivism are few (-sha), while the positive color of some suffixes (-kai/-kei,-chyk/chek) is pretty stable (Gimaletdinova, 2005).

The suggested description is necessary to ensure that students feel comfortable about using connotative words meanings basing on their external, formal expression, and at the same time, taking into account the conformity of certain external expression with certain connotative meaning, that they use emotionally colored words in their speech better and more productively.

It is noted, that the most common means of expressing connotations in Russian are suffixes of subjective assessment. The system of these suffixes can be shortly shown as this: suffixes used to express positive emotions

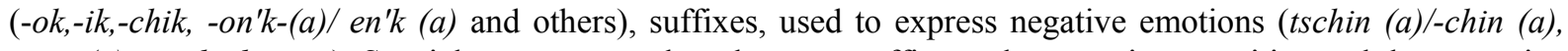
-atin (a), an,-lovk-, etc.). Special cases occur when the same suffix can be sometimes positive and then negative (for example,-onk (a): nozhonka, ruchonka, mal'chonka-tender, with little, old ones; knizhonka, odezhonka, bumazhonka--pejorative). 
Productivity of the suffixes, creating forms of subjective assessment can be different not only with nouns, but also with adjectives and adverbs (-en'k/-on'k (iy)-ekhonek-/-okhonek-,-eshenek-/-oshenek,-jusen'k (iy), etc.) A special focus is made on a variety of noun suffixes of common gender, having in most cases disapproval

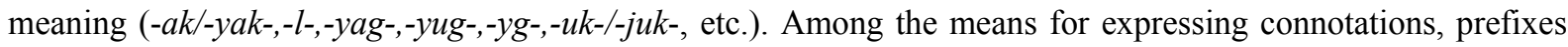
and prefixoids are specified.

There are a significant number of complex words with connotative color, many of which are old slavisms (blagovospitanniy (genteel), dobroporyadochniy (respectable), korystolyubie (greed), etc.).

There is lexics with coloring without formal indicators (ochi (eyes), nevezhda (an ignorant person), drandulet (a bad old vehicle), izverg (a cruel monster), etc.).

At the class, one may use slides with tables ("Suffixes of a positive assessment", "Suffixes with negative assessment" "Prefixes of subjective assessment", etc.).

It is offered to promote students' activity at the class with the following tasks: a) to find colored words of this or that word-formation structure in the texts and dictionaries and describe their 'color'; b) to form words with distinct connotation from the given words foundations (written on the board or designated on a slide) by means of suggested suffixes. After the task is completed there is a discussion held to clarify which affixes helped the students constitute emotionally -evaluating lexemes and which affixes weren't used.

\subsection{Situational Context of Lexics Usage}

The stage, which explores the theme "Functioning of the Russian language marked lexics", is important for the formation of communicative abilities and skills in unity with the concepts of socio-cultural stereotypes of the Russian speech behavior. Here the conditions for its usage in speech practice are defined.

The basic situations of the marked words' functioning in Russian and Tatar speech are identified, for example, a) when an adult is speaking to a child and in general when speaking with children, especially young children, b) in conversation, in which the absent person (of any age), his actions, deeds, etc. are evaluated.

We consider T. A. Balykhina's idea about speaking the second language very true. She claims it can be learnt more effectively if 'the training material, its formal and pragmatic characteristics are practice-oriented and adapted to the learners' needs; if the applied techniques are modified according to the specific circumstances and if more value is given to the situational context and visual context of communication (Balykhina, 2007, p. 185).

The training provides illustrations from the fiction, reveals the specific characteristics of the marked words usage in this or that speech sphere field taking into accounts the socio-cultural context. It is important to inform students that using the marked word (diminutive, pejorative) does not only obeys the common speech intention to express the emotional relationship to something, usually to an animate subject, but also takes into account the appropriateness/inappropriateness of its usage in a certain situation, reflecting behavioral stereotypes typical of Russian people.

\subsection{Practical and Laboratory Classes}

For the practical exercises, we suggest a system of conditionally-speech, speech and situational exercises, overall 21 exercises. "It includes exercises on identifying words' connotative peculiarities (poor-thing and moneygrubber), on selecting emotionally charged units from the list of words and on determining their coloring, on search of the marked words in fiction and journalistic texts, on selecting connotative synonyms and antonyms, on synonyms groups' analysis, on derivation, the defining the situation of a conversation in which you can or cannot use the specified words, on choosing the right marked word for the given speech situation from a list of other colored words, on composing the dialogue with the specified connotationally-unified words, on transforming utterances giving them the opposite emotional-style coloring and others" (Tirigulova \& Zakirova, 2014, pp. 186-189).

Methodologically, when teaching this topic as part of the basic course in the Turk-speaking audience interactive learning methods should take an important place. They should be based on "the modeling situations method, formulating and making a decision in the conditions typical for the specialist's future professional activities" (Altaeva, 2012).

Among such methods, in our view, the basic ones are role playing, small-group and pair work, work with visual aids, discussions, creating problematic situations, creative tasks (Lagutkina, 2012, p. 12; Salova, 2012; Shaklein, Ryzhova, 2008, p. 258). Designated methods stimulate not only thinking and cognitive but also speech activity of the students.

Particular attention should be paid to the selection of texts, which should be chosen from materials on the 
Russian people's history and culture, samples of fiction. As it was mentioned above, at the classes where Russian is the second language, teaching the language means not only teaching the communication techniques or knowledge of the world, but also teaching means of initiation to national cultures, to the spiritual values of the contacting people.

The methodology for conducting practical classes makes much emphasis on working with the explanatory dictionaries of the Russian language. At the end of the course, it is suggested to conduct a laboratory lesson on "Marked vocabulary study using the explanatory dictionaries". This theme implies the following purpose and content of training: a) to analyze dictionaries and determine, which colour the words in this list have- positive or negative, what differences there are in the vocabulary definitions; b) to clarify the connotative semantics given by the dictionaries basing on the lectures. The task is individually specified by means of basic language material variation: a) a specific suffix study; b) a separate list of words analysis (20-30 units).

At the same time with setting the purposes of the work, with specifying the theme, a certain writing form is given, which should reflect the results of the work- description-plan of the conducted micro-survey and sample tables, which are filled with the results of the words' statistical processing.

\section{Results}

The materials prepared by the authors of this study served the base for a pilot training among Turk-speaking students in the KFU Institute in Yelabuga, in 2014.

The experimental training included a stating profile, teaching experiment and the final profile check.

The stating profile study was carried out to study the students' learning and mastering level concerning marked vocabulary of the Russian language. The test covered two groups of fifty people.

The following data were obtained as a result of the control test work check. The study of the obtained results revealed the Turkic-speaking students' awareness of emotionally and stylistically marked vocabulary; and allowed to determine which aspect of the connotation presents the greatest difficulty for learning and which difficulties students face when analyzing the marked words in the text.

The stating profile research fully confirmed our hypothesis about the Turk-speaking students' difficulties in their learning the marked vocabulary, which are caused, in our opinion, by a number of reasons, such as: 1) insufficient study of the problems in teaching the marked lexics in the Russian educational literature (students' school preparation on the topic is almost zero); 2) there is no compactness or clarity in presenting the material in textbooks; 3) lack of common terminology; 4) there are few exercises and they are of the same type; 5) lack of the functional aspect of the material study.

The teaching experiment was designed to test the effectiveness of the developed system of tasks by criteria of their availability to the students, as well as their feasibility and effectiveness.

The results of the written work when comparing the training and control groups are presented in the following table:

Table 1.

\begin{tabular}{lllllllll}
\hline Experimental group & & \multicolumn{1}{c}{ Control group } \\
\hline Mark & 1 & 2 & 3 & Sum & 1 & 2 & 3 & Sum \\
Excellent & 1 & - & - & - & 1 & - & - & - \\
Good & 15 & 15 & 11 & $15(60 \%)$ & 7 & 5 & 1 & $5(20 \%)$ \\
Satisfactory & 7 & 7 & 9 & $7(28 \%)$ & 15 & 15 & 6 & $15(60 \%)$ \\
Bad & 2 & 3 & 5 & $3(12 \%)$ & 2 & 5 & 18 & $5(20 \%)$ \\
\hline
\end{tabular}

$1,2,3$ - parameters of giving marks;

1 - defining the marked lexics in the text;

2 - stating the general emotional color (positive, negative, mixed);

3 - specifying colour shades (disapproving, tender, joking, etc.).

As you can see, the results of experimental group students are higher than of the control group students. 


\section{Discussion}

During the work on the proposed methodology, the students were noticed to significantly activate the marked vocabulary usage at the practical training. In addition, as it had been expected, explanatory dictionaries of the Russian language were actively used, which, according to our observations, contributed to the assimilation of many marked units greatly. Therefore, the final verification of the training group students showed greater preparedness than the control group students did to execute the written work, which in terms of the given tasks partially repeated the lab class.

The results of the training experiment confirmed the assumption that the proposed content of the lectures and the exercises system are available and feasible for students, which was proved by a number of positive responses compared with unsatisfactory answers. During the lessons the training group students showed a high enough speech activity using the newly-introduced lexical units (in the dialogues, statements constructing). In addition, the training group students showed higher abilities and skills in working with texts and dictionaries on selection and characterization of emotionally and stylistically marked vocabulary that was confirmed by the results of the lab class, and the written control work.

The expanded and updated structure of the section allowed the students to learn the corresponding theory better and to apply it in practice successfully.

\section{Conclusion}

In conclusion, let us summarize our study results and note that the marked vocabulary of the modern Russian language, which is a huge number of words, presents much difficulty for the Russian language non-native learners because of the large number and insufficiently differentiated symptoms of certain types of coloring. The educational literature on the basic course "Modern Russian language," doesn't pay necessary attention to this group of words.

Description of the colored words of the Russian language is hardly focused on the Turk-speaking students: factual and linguistic material is not presented enough. To improve the teaching of this subject in the course of "Contemporary Russian language" compared with the traditional, typical material presentation in textbooks, in Turkic-speaking audience it is need to present the extended and updated classification of types and subtypes of colored Russian words, to enhance such aspects of marked words' description as forms of various connotations expression, their relation to the whole lexical system of the Russian language, to add their functional use to the description of these units.

Methodologically, the teaching of this subject in the theoretical course for Turk-speaking students groups should focus on a contrastive typological approach to learning vocabulary, interactive teaching methods, problem-based learning methods, electronic educational resources and widespread usage of the Russian language explanatory dictionaries.

The experimental training conducted in accordance with the proposed content and methods of teaching, in general showed the efficacy and material availability for Tatar students.

In the further teaching them the Russian language lexics, we consider perspective to update the textbooks, teaching methods, to use of information and communication technologies and to create an electronic (multimedia) educational resource for this section.

Therefore, the study of emotional and evaluative lexics of the Russian language in the comparative perspective, with various traditional and modern technology application, allows identifying common and specific in the language world picture of the Russian and Turkic languages native speakers, simultaneous forming linguistic, communicative, cultural and pragmatic competence of Turkic-speaking students.

\section{Acknowledgements}

The work is done at the expense of the grant within the framework of the state support of Kazan Federal University in order to improve its competitiveness among the world's leading scientific and educational centers.

The work is performed according to the Russian Government Program of Competitive Growth of Kazan Federal University.

\section{References}

Altaeva, G. A. (2012). Using interactive methods in teaching Russian as the second language. Russian language and culture in translation mirror. Materials of III international scientific and practical conference. M.: 
Graduate School of Ttranslation, MSU. Retrieved February 2, 2015, from http://www.esti.msu.ru/netcat files/userfiles/kuzma/forummaterialy/12/Unified

Arshinova, N. I. (2007). Formation of foreign language competence of University students by means of computer technology. PhD thesis. Petrozavodsk, 2007.

Bakeeva, N. Z. (1983). Structural-typological characteristics of the languages from the methodological point of view (pp. 19-28). Linguistic basis of language teaching. Moscow: Nauka.

Balykhina, T. M. (2007). Methodology of teaching Russian language as non-native (new): A training manual for teachers and students (p. 185). M.: Publishing House of the Peoples ' Friendship University.

Bochina, T. G., \& Habibullina, E. V. (2012). Modern educational technologies in the Russian language teaching as the second language: the concept of professional development programs for teachers of general education schools. Philology and culture, 2. Retrieved from http://cyberleninka.ru/article/n/sovremennye-obrazo vatelnye-tehnologii-v-prepodavanii-russkogo-yazyka-kak-nerodnogo-kontseptsiya-programmy-povysheniy a-kvalifikatsii

Fattakhova, N. N. (n. d.). The Russian language as non-native in the Republic of Tatarstan: Problems teaching at school. Retrieved February 18, 2015, from http://kpfu.ru/staff_files/F1988583143/Prepodavanie. russkogo.i.rodnogo.yazykov.v.Respublike.Tatarstan.pdf

Fattakhova, N. N., \& Yusupova, Z. F. (2012). To the problem of contrastive-typological study of Russian and Turk languages and cultures. Philology and culture, 3(29). Retrieved February 15, 2015, from http://gigabaza.ru/doc/26348.html

Fedorov, S. V. (2012). Study of the Russian language as a tool of foreign students' inculturazation. Teaching Russian as a foreign language: St. Petersburg pedagogical experience: a collection of articles. St. Petersburg: St. Petersburg APPO. Retrieved February 18, 2015, from http://window.edu.ru/library/pdf2txt/971/79971/ 60342/p.12

Gimaletdinova, G. K. (2005). Expressiveness of noun suffix derivatives in English and Tatar languages.

Ibragimova, E. R., \& Tirigulova, R. H. (2014). Problems and Perspectives of Bilingual Education in Republic of Tatarstan. Middle-East Journal of Scientific Research, 20(6), 677-680.

Khromov, S. S. (2012). Russian as a non-native language in information educational space of modern Russia. Philology and culture, 2(28). Retrieved December 14, 2014, from http://cyberleninka.ru/article/n/russkiyyazyk-kak-nerodnoy-v-informatsionnom-obrazovatelnom-prostranstve-sovremennoy-rossii

Lagutkina, T. A. (2012). Role of didactic games in the language teacher's work on expanding the foreign students' vocabulary at Russian language lessons. Teaching Russian as a foreign language: St. Petersburg pedagogical experience: a collection of articles. St. Petersburg: St. Petersburg APPO. Retrieved February 2, 2015, from http://window.edu.ru/library/pdf2txt/971/79971/60342/p.12

Salova, Z. V. (2012). Teaching Russian as a foreign language. Festival of pedagogical ideas "Open lesson". M.: "The first of September". Retrieved January 4, 2012, from http://festival.1 september.ru/articles/518211

Sayakhova, L. G. (2014). Concept as a unit of linguo-culturology, cognitive linguistics and linguo-didactic. Bulletin of the Bashkir University, 19(3). Retrieved February 20, 2015, from http://bulletin-bsu.com/arch/ 2014/3/5-18/

Shakirova, L. Z., \& Sabatkoev, R. B. (2003). Methodology of teaching Russian language (on the material of the national schools) (p. 376). SPb.: Education; Kazan: Magarif.

Shaklein, V. M., \& Ryzhova, N. V. (2008). Modern methods of teaching Russian language to non-Russians: Stud. Manual (p. 258). Pm: Peoples' Friendship University. Retrieved January 28, 2015, from http://weblocal.rudn.ru/web-local/uem/iop_pdf/170-Ryzhova.pdf

Shalimova, N. E. (n. d.). Several issues of studying the Russian language as non-native. Psycho-pedagogical and methodological requirements to a modern lesson of the Russian language as non-native. Social network of educators. Retrieved November 20, 2014, from http://nsportal.ru/shkola/russkiy-yazyk/library/2013/12/04/ nekotorye-voprosy-izucheniya-russkogo-yazyka-kak-nerodnogo

The federal target program "Russian language" in the 2011-2015 period. Decree of June 20, 2011 \# 492//Ministry of education and science of the Russian Federation. Retrieved February 23, 2015, from http://old.mon.gov.ru/dok/prav/obr/8717/ 
Tirigulova R. H., \& Zakirova, O. V. (2014). A contrastive typological approach to the study of the Russian language vocabulary by the Turkic-speaking audience. Philology. Questions of theory and practice. Gramota, 10(40), 186-189.

Yusupova, Z. F. (2012). Language and cultural principles implementation in the educational literature in Russian for Turk-speaking audience. Philology and culture. Philology and culture, 28. Retrieved February 23, 2015, from http://philology-and-culture.kpfu.ru/?q=node/999

\section{Copyrights}

Copyright for this article is retained by the author(s), with first publication rights granted to the journal.

This is an open-access article distributed under the terms and conditions of the Creative Commons Attribution license (http://creativecommons.org/licenses/by/3.0/). 